\title{
The Influence of "Cynicism" on College Students of Contemporary Art and Its Performance
}

\author{
Renfei Wang \\ Chengdu University \\ Chengdu, China
}

\begin{abstract}
Cynicism is infiltrating colleges and universities and affecting the ideas and behaviors of art students taking the "information explosion" and the rapid development of "art examination economy" as a carrier. The improvement of understanding the "cynic" phenomenon among art college students and the enhancement of their ideological guidance are the issues that should be paid attention to in current college education. This paper interprets the "cynic" phenomenon among art college students from the following three aspects: the evolution of connotation, ways of spreading and performance forms of cynicism.
\end{abstract}

Keywords-cynicism; art college students; art examination economy

\section{INTRODUCTION}

"Cynicism" is one of the four major schools of thought in ancient Greece, and its believers were known for their attitudes of living like "dogs". In today's society which emphasizes material wealth, the connotation of "cynicism" has changed. As a social and cultural concept, "cynic" represents a tendency of value in today's society, that is, "not rejective understanding, unresisting awareness, and disagreed acceptance". This concept has entered universities and colleges on the carrier of "information explosion" on the Internet and the rapid development of "art examination economy", which affects the ideological morality and behaviors of art college students, and a number of "cynics", have emerged. They have great enthusiasm for professional study and campus life, but in the face of real interests, they also become tactful, utilitarian and concern very much about personal interests. Therefore, the improvement of understanding the "cynic" phenomenon among art college students and the enhancement of their ideological guidance are the issues that should be paid attention to in current college education.

\section{The CONNOTATION AND EVOLUTION OF "CYNICISM"}

The English word "cynicism" is often translated as "cynic". In the 5th century AD, Socrates' disciple Antisthenes founded the "cynicism" school. "Cynics" mean "dog-like persons", and there are two versions about the origin of it: first, it was named after Antisthenes' speech at a stadium called "Gu Nor Saggers" (meaning "quick dogs"); the second is because Antisthenes and his followers lived a life as simple as wild dogs, contrary to ordinary people. Antisthenes' disciple Diogenes inherited and promoted cynicism. The cynicism school, together with the Epicurean school, the Stoic school, and the Neo-Platonic school, is called the four major philosophical schools of ancient Greece by later generations.

The ancient cynics represented by Antisthenes and Diogenes advocated human beings to be "independent, selfcontrolled, and self-sufficient". They believed that the ultimate goal of human beings to do all things was to "pursue the virtues", because virtue was the highest level of "goodness", and only by owning virtues, could people be happy. Therefore, cynics objected to pursue enjoyment in real life and advocated that people should return to lead a natural and simple life. They despised authorities, ignored dogmas, did not believe in all existing values, rejected all worldly desires, and pursued the independence and happiness of "humans" through being cynical in their external behaviors.

With the rapid development of society and the continuous improving of material level, people's various desires such as selfishness, greed, etc. are also expanding. Out of the excessive pursuit and protection of their own interests, some cynics have given up the rejection of "secular" and begun to accept the "secular". Under the cynical appearance, they are doing things in another different way, hiding their true face of mercenary and sarcastic ridicule. They understand what is right and wrong, good and evil, true and false, beautiful and ugly in the society, but "act as if they don't know it", being unable to "achieve the unity of knowing and doing" like the ancient sages.

\section{The Two WAYS OF SPREADING OF CYNICISM AMONG ART COLLEGE STUDENTS}

There are two main ways for cynicism to spread among art college students. One is on the carrier of the "information explosion" brought about by "globalization of the Internet"; the second carrier is the "art examination economy" that emerges due to the "art examination fever" in China.

Nowadays modern communication and information technologies are becoming more and more intelligent, which makes the "Internet" become an indispensable part of people's social life. In the current era of "information explosion", on the one hand, due to the positive characteristics of information on the Internet, such as the openness and rapidity, more and more art college students use the Internet to study professional knowledge and skills, deal with their various affairs, know about hot issues, and make friends. Through the Internet, they 
can quickly master the cutting-edge researches and development trends of their own disciplines; they can also share their artworks on the online platforms, find friends who have the same interests in arts with them and get a sense of belonging on the Internet. On the other hand, information on the Internet also has negative characteristics such as anonymity and falsity. Various online public platforms, while spreading news and hot issues, inevitably pass on "Internet buzzwords" and "Internet violence" with the characteristics of "cynicism" to art college students.

In the early 1990s, the state began to advocate quality education, which made the "art fever" emerged in China. With the deepening of the reform of higher education system, the proportion of state funding in education funds has been decreasing year by year, which seriously restricts the development and construction of colleges and universities. In 1998, China passed the Higher Education Law, which gave colleges and universities more autonomy in running schools. Under the situation that the education funds were insufficient and the state gave colleges and universities more autonomy in running schools, many universities in China have targeted the art majors with higher tuition fees. As a result, the enrollment in art majors was expanded, and the "art examination fever" also emerged. The "art examination fever" has nurtured the "art examination economy", and thousands of art examination training organizations have emerged constantly. They are not only the production bases of contemporary "art students" but also the breeding grounds for "cynicism". For a long time, the enrollment of art majors has the characteristics of "attaching importance to professional competence, taking little account of cultural level, and low enrollment mark". It makes some parents and students with weaker cultural performances regard attending art examinations as a speculative way to get college degrees. Therefore, these families are willing to pay several times more than normal tuition fees to let their children "learn" art. On the other hand, the "art examination training organizations" attract the influx of investors and the envy of art students with its "short cycle" and "high return" mode. This fast money-earning method allows art students to prematurely perceive the "high profits" brought about by the "market economy". However, due to their immaturity in values, this part of art students, after entering colleges and universities, regard colleges and universities as the market, take "equivalent exchange" as the principle of their actions, and are "selfcentered" in minds, "take making money as the only purpose" of their behaviors, becoming "selfish" cynics.

\section{The ThreE MANifESTATIONS OF "CYNICISM” AMONG ART COLLEGE STUDENTS}

Because art college students have outstanding selfawareness, utilitarian learning attitude, and relatively perceptual ways of thinking, their thoughts and behaviors are more susceptible to external influences and interferences, showing the "cynic" characteristics such as "utilitarian value orientation", "socialized and tense interpersonal relationships", "weak target consciousness and vague self-positioning", etc. :

\section{A. The Utilitarian Value Orientation}

With the "art examination fever" continuing to heat up, the value orientation of art college students is becoming more and more utilitarian. Scholar Ben $\mathrm{Xu}$ believes that the characteristics of cynic culture are to "say things in one way and behave in another". Cynics have a clear understanding of the outside world, but can't achieve "the unity of knowing and doing". When there is a big gap between ideals and the reality, cynics will show a "not rejective understanding, unresisting awareness, and disagreed acceptance" to the reality.

First of all, for some art college students, there are problems such as the high cost of participating in art examination training and the uneven quality of training teachers behind the "art examination fever". These problems indirectly led them to form a mindset of "professional competence is the most important", "it is not easy for taking part in art examinations" and "it takes much money to learn art". Therefore, when they found that they could not change the existing "rules", they chose the "disagreed acceptance". Under the influence of this inertia thinking of "cynicism", the values of this group of art college students reflect a strong characteristic of "material pragmatism". They regard whether they can "make profits" as the only purpose and meaning of all their actions, so they attach great importance to the learning of professional courses, and take little account of the study of cultural courses. In the participation of campus activities, they value material gains above justice, and if there is no profits, they will not participate. Secondly, the "cynic" thinking makes them pay too much attention to the immediate interests, which not only allowed some art college students to have an expectation and pursuit of material life prematurely, but also gave birth to their short-sighted and eager for immediate interest mentality. And once their material needs can't be met in reality, they may easily lose themselves and go astray. In addition, because the legal awareness of art college students is relatively weak, while working part-time has become their primary choice to spend spare time, fraud cases such as "campus loan", "telecom fraud" and "part-time work fraud" have also occurred repeatedly among them.

\section{B. Socialized and Tense Interpersonal Relationships}

As a product of the development of the times, the Internet has made campus life more convenient. However, under the current situation that the Internet supervision mechanism needs to be perfected, the "cynic" influence bought by the Internet on the thinking and behaviors of art college students is also very obvious. On the one hand, the Internet is different from the real life, which allows the rich emotions of art college students to be released and satisfied in the virtual world. Especially the entertaining "talent-search shows" that emerged in China in 2005 and the webcast that is currently receiving much attention, these social phenomenon of "civilian get branded" and "star plebification" which center on "individuals" have not only satisfied the psychological appeals of art college students to show themselves, but also left a broad imagination space for their interpersonal interactions on the Internet. In order to gain more attention from the public and to gain more benefits, some art college students bring the sleek and sophisticated ways of dealing with affairs in society to the campus. In the 
participation in campus activities and class affairs, in order to get the opportunity for display, or in order to obtain the honors and awards, etc., they divide into small groups, conduct mutual suspicion and make intrigues, becoming the "cynics" who comply in their appearance but oppose in heart. On the other hand, the Internet is an important approach for art college students to spend their spare time. Currently, the content on the Internet is complex, full of cynical online buzzwords and tempting false information. Although the Internet has opened the door for students to know the outside world, it has also closed the window of "communication". When art college students are accustomed to the online knowledge that can be easily acquired, and when they are used to living in the selfenclosed space, the distance between teachers and students, and the distance between the students themselves are becoming farther and farther. At the same time, these art college students usually have a strong sense of self-protection. In addition, their social intercourse scope is generally narrow, and most of them lack communication experience and skills, so when they should act as the sender or receiver of information, often there will be communication barriers. Although they are aware of the negative impact of the Internet, due to the cynicism of "not rebellious awareness", their thoughts and feelings cannot be communicated and vented in time, causing that they can't find friends that they can talking to in the real world after leaving the Internet. The psychological imbalance, loneliness and confusion caused by poor communication, and the lack of effective communication make it easy for the public to misunderstand the thoughts and behaviors of art students. Poor communication can also cause them to be psychologically imbalanced, and cause them to fall into emotional fluctuations and behavioral deviations, which in turn can make their interpersonal relationships tense, and even lead to their depression, loss of interest, negative selfevaluation, etc.

\section{Weak Target Consciousness and Vague Self-positioning}

There are mainly three ways of formation of professional literacy of art college students: First, the students have been learning art professionally since their childhood. Learning art professionally is their main task. Such students have solid basic skills and strong professional competence, who are known to the society that they have been obtaining professional training since their childhood. Second, the students have been exposed to professional art training when they are children. They have certain basic skills. For some reason, they decide to attend the "art examination" at the high school stage. These students have relatively weak professional ability, but have strong adaptability in learning. The third kind of students are the ones who have not received professional art training and have "been encouraged" to enter the art training classes and attend the "art examination" due to their poor performance in cultural lessons. For this group of students, learning "art" is just a springboard for obtaining a college degree, and because of this, they are also the easiest to show "cynic" qualities.

There are also talented and hard-working students among these students, but from the professional teachers' point of view, most of them lack stamina and are hard to train after entering universities. In the face of the increasingly severe employment situation, such art students also feel confused when they are graduating. The reasons are, first of all, their purpose of learning is not pure. For this type of students, the purpose of learning is just to get a diploma, but not to improve their professional levels; Secondly, their attitude of learning is not firm. Their enthusiasm of "three minutes of heat" in the training class quickly cooled down after they have entered the schools and received the boring basic skill training, which made them lose their professional interest and confidence while neglecting their responsibility as professional students. In addition, regardless of the students' own feelings, some parents have planned and formulated the employment direction and development goals that students are not satisfied with for their children, which is also one of the important reasons why students have a negative attitude towards professional study and become "cynics". The weak target consciousness, the vagueness of self-positioning, and the inertia thoughts have made this group of students form a "cynic" attitude of "muddling along" in mind and "getting adrift" in behaviors, which greatly restricts and influences the future personal development and career planning of art students.

\section{CONCLUSION}

Generally speaking, the phenomenon of "cynicism" among art college students is a joint effect of the rapid development of society and the collision of contemporary pluralistic values. It is not difficult to see that for art students, the rapid development of social economy, culture and online media is conducive to their broadening of horizon, self-improvement, and the establishment of consciousness of innovation, entrepreneurship, and self-improvement; but on the contrary, this status quo also bought about problems of "utilitarian value orientation", "tensioned interpersonal relationships", etc, making art students show the characteristics of "cynicism" of the disunity of knowing and doing. For the ideological and political educators in colleges and universities, at the crossroads of social transition and the influx of a large number of Western cultural thoughts and values, they are not only enjoying the convenience bought by the rapid development of society to their work, but also facing the severe challenge of how to carry out the "thought-leading" work for students.

\section{REFERENCES}

[1] $\mathrm{Xu} \mathrm{Ben,} \mathrm{The} \mathrm{cynicism} \mathrm{in} \mathrm{mass} \mathrm{society} \mathrm{of} \mathrm{today's} \mathrm{China[J],} \mathrm{China}$ Economic Weekly, 2001 (17). (in Chinese)

[2] Li Fan and Li Decai, Reflections on the Innovation of Network Ideological and Political Education Methods [J], Journal of Ideological and Theoretical Education, 2012 (6). (in Chinese) 